\title{
Variation In Frequency And Share of Duration of Rainy Days In Iran's Precipitation
}

Hossein Asakereh ( $\square$ asakereh@znu.ac.ir )

University of Zanjan https://orcid.org/0000-0001-7699-0547

\section{Saeideh Ashrafi}

University of Zanjan

\section{Research Article}

Keywords: Rainy day, precipitation duration, precipitation frequency, spatial variation

Posted Date: November 17th, 2021

DOI: https://doi.org/10.21203/rs.3.rs-1030545/v1

License: (9) This work is licensed under a Creative Commons Attribution 4.0 International License. Read Full License 


\title{
Variation in frequency and share of duration of rainy days in Iran's precipitation
}

\author{
Hossein Asakereh $(\mathrm{PhD})$
}

University of Zanjan, Department of Geography, Zanjan, Iran asakereh@znu.ac.ir: Corresponding Author

ORCID: 0000-0001-7699-0547

Saeideh Ashrafi

University of Zanjan, Department of Geography, Zanjan, Iran

Acknowledgements: We would like to thank the Islamic Republic of Iran Meteorological Organization (IRIMO) for providing us with the daily precipitation. 


\title{
Variation in frequency and share of duration of rainy days in Iran's precipitation
}

\begin{abstract}
In any region, climate change can be manifested in the form of various characteristics of climatic elements. To investigate the possible precipitation variations, as a sign of climate change in Iran, in the present study, the frequency of duration of rainy days was examined as a precipitation characteristic. To this end, gridded data of precipitation were used for the period of 1971-2016, and days with the precipitation of more than $1 \mathrm{~mm}$ were considered as rainy days. Considering the frequency of the rainy days, it was revealed that during the study period, one to thirty six-day duration of precipitation occurred in the country. One-day duration had the highest frequencies and covered the vastest area, while thirty six-day duration had the lowest frequencies and covered the smallest area. Accordingly, the one-day duration played the most significant role in annual precipitation. The share of these types of rainfalls in the low-precipitation parts of the country was more than $80 \%$ and in some areas. The findings also revealed that there was an increasing frequency of short-term, especially two-day duration, in large parts of the country, and a decrease in the long-term duration. The results showed that latitude and longitude, respectively, had the most significant impact on the frequency distribution of the duration of rainy days. Latitude had a direct effect (except in terms of the share of one-day duration of annual precipitation) and longitude had an inverse effect (except in the share of one-day duration of annual precipitation).
\end{abstract}

Keywords: Rainy day, precipitation duration, precipitation frequency, spatial variation

\section{Introduction}

As one of the most important climatic elements in Iran, precipitation has always had its own unique complexities. These complexities are mainly due to the location and geographical features of the country, something which have caused inequalities in the temporal and spatial distribution of precipitation (Alijani et al. 2014). The significance role of precipitation in water supply has drawn the attention of 
climatologists to this climatic element, its characteristics and changes. One of the most important features of precipitation in Iran is the temporal and spatial variations of rainy days and their duration, which have been examined only in few studies to date.

A rainy day refers to a day with at least one millimeter of precipitation (Douguedroit 1987; Romero et al. 1998; Lazaro et al. 2001; Kutiel and Trigo 2014; Bichet and Diedhiou 2018; Vaittinada Ayar and Mailhot 2021) in which all precipitation features exist in the atmosphere (Masoudian and kavyani 2008). Therefore, the persistence of these features can lead to continuous precipitation for several days. Examining the duration of precipitation and the amount of precipitation received during consecutive days can provide useful insight into water resources in a given area. For example, long-term duration of rainfall can have a significant impact on the surface and underground water resources and can reduce the effect of evapotranspiration, as with the persistence of precipitation, the moisture in the atmosphere increases and, in turn, the moisture capacity of the atmosphere decreases (Kavyani and Alijani 2001). Duration of precipitation and its variations have been the focus of some studies around the world. For example, Naseri and Modarres (2009) investigated the dry period in Isfahan Province, Iran using non-parametric Mann-Kendall methodology, the results of which showed a jump in dry days of time series in 1980, especially in the eastern parts of the province. Moreover, Singh and Ranade (2010) examined wet and dry periods in India and found that during the last years of the study period, precipitation periods had become shorter and the precipitation rate in each period increased. Also, the rainy season started a few days earlier. Ratan and Venugopal (2013) also examined the characteristics of wet and dry periods in tropical regions of the world. The results of their study showed that in dry areas one- to -five day duration had the major share in annual precipitation and in wet areas thirty-day duration had the largest share in annual precipitation. Furthermore, Vinnarasi and Dhanya (2016) examined variations of extreme rainy and dry periods in the Indian seasonal precipitation during the period of 1901-2013. The results showed that in western areas, the duration of wet periods had a decreasing trend and the duration of dry periods had a significant increasing trend. In arid areas, on the other hand, the reverse behavior was observed in wet areas. A jump in the share of heavy seasonal precipitation also occurred in 1950. In another study in china, Duan et al (2017) 
examined variations in the duration of dry days in China, the results of which showed a significant increase in the frequency of dry days in the cold and warm seasons in the southeastern and southern areas of China, respectively.

A study examining dry periods in Russia conducted by Ye and Fetzer (2019) indicated that there is a tendency toward longer dry periods in Russia due to the higher temperatures in summer. Nazaripour et al (2011) also examined the spatial patterns of precipitation duration in Iran. The results of the study showed that the maximum number of rainy days of all parts of Iran and the maximum precipitation rate of a large part of Iran are caused by one-day precipitation. In addition, Asakereh (2013) examined the trend of dry and wet seasons in Zanjan, Iran and found that there is no specific trend in the frequency of dry and wet seasons of Zanjan. Further, Mansuri and Doostan (2019) had an investigation into precipitation patterns with two and three-day duration in the west of the Iran. In the obtained patterns, the meridional movement of westerly winds was predominant in the Middle East. Gholizadeh and Hamidi (2020) investigated the variations of precipitation duration in the Kordistan Province, Iran. This study showed a decrease in the duration of precipitation in the rainy months and an increase in the dry months.

In many studies, the precipitation duration was considered on an hourly basis. In the meantime, some studies such as Nunn (1929) (in relation to the precipitation duration in Baltimore) was conducted based on stations. But the majority of studies (Shands 1947; AghaRazi 2007; Behyar et al 2013; Ghafouriam and Telvari 2010; Liu 2011) carried out over large areas.

Due to variations in precipitation behavior and its characteristics in recent years leading to flood and drought risks in Iran, investigation into precipitation is of utmost importance. One of the important characteristics of precipitation in Iran is the duration of rainy days. In this study, the frequency of precipitation duration and its variations were studied based on regression methods for the period of 1970 to 2016.

\section{Data and methodology}

\subsection{Study area}

Iran is located in the southwest of Asia and in the desert belt of the planet, where most of the arid and semi - arid regions of the world are located (Alizadeh 2009). 
Therefore, the large parts of the center, and the east and southeast of the country are arid areas. Fig 1 shows the topographic map of Iran. As can be seen from Fig 1, two mountain ranges form the major terrains of Iran with west-east (Alborz mountain range) and northwest-southeast (Zagros mountain range) directions. Each of these terrains plays an important role in the distribution of moisture and precipitation in Iran. The Alborz range encloses the humidity of the Caspian Sea on the northern slope, and the Zagros is a barrier to confine the humidity of the Mediterranean Sea reaching low-lying areas in the centre of Iran. Therefore, the southern slope of Alborz and the eastern slope of Zagros are different in appearance from their opposite slopes. The northern slopes of Alborz and the western slopes of the Zagros are regions with high precipitation. Therefore, it can be suggested that in Iran, the distribution of heights and their directions control the precipitation distribution. Accordingly, the borders of Iran's climatic zones match mainly the topographic borders (Masoudian and kavyani 2008). The southeastern part of Iran is affected by monsoon systems in the warm season and part of precipitation results from these systems. However, the factors involved in rainfall distribution in Iran can be divided into internal (local) and external (circulation) factors, each of which contributes to the formation and distribution of precipitation.

\subsection{Data}

The daily precipitation data of 2188 synoptic, climatic and rain gauge stations of the Meteorological Organization were obtained for the period of 1951 to 2018 (i.e. 24837 days, equaling 68 years). These data were converted into a matrix of time-place mode. In this case, the dimensions of the matrix were 24837 rows (time; days) and 2188 columns (place; meteorological station). The average number of active stations per day is 488 . For various reasons, the number of active stations was not constant during the under study period. The spatial density of the stations decreased from west to east and from north to south (Fig 1). The spatial density of the station varied between zero and 4 per $100 \mathrm{~km}^{2}$. 


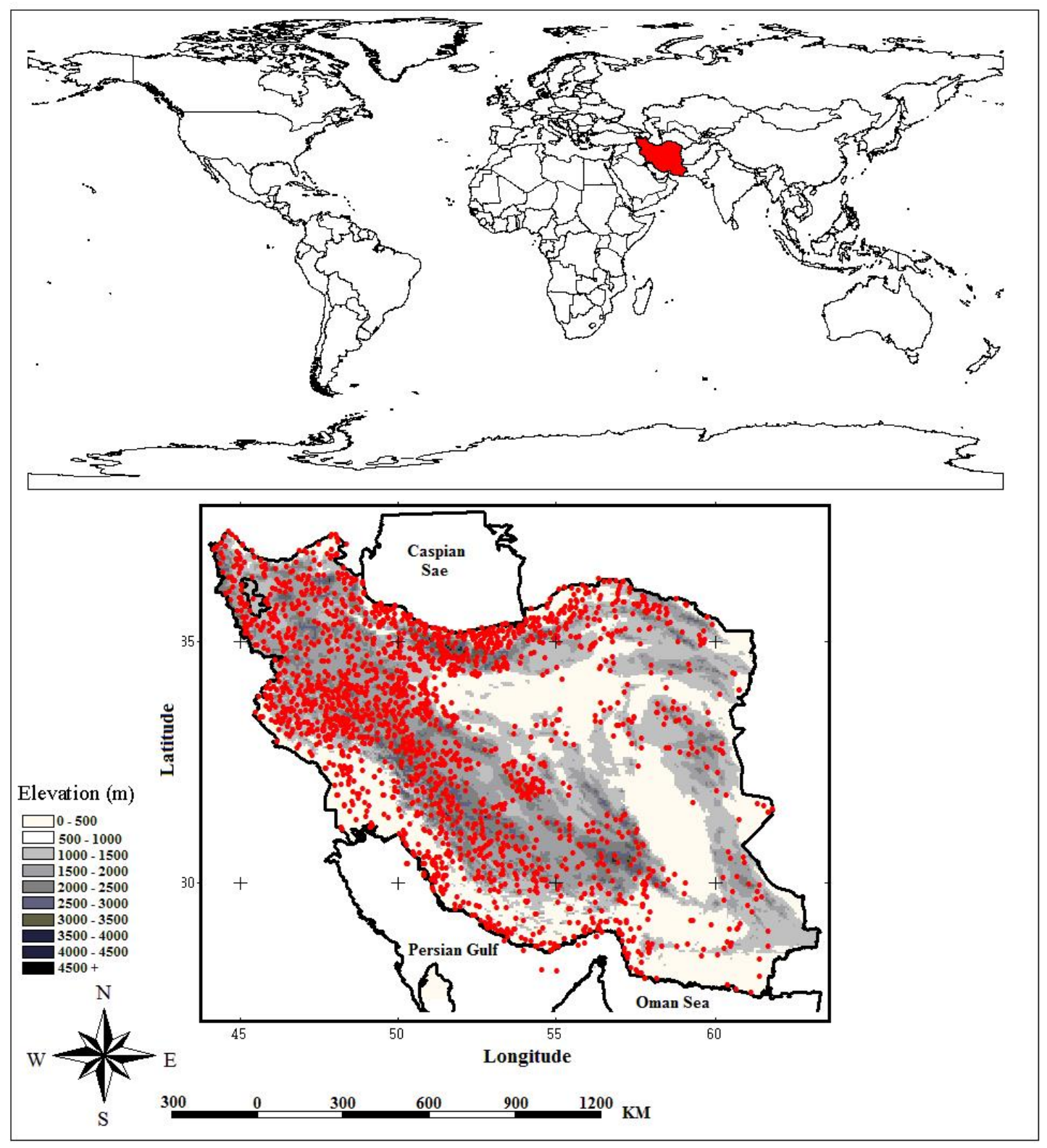

Fig 1 Location of Iran, topography feature and distribution of stations used in current study

\subsection{Methods}

To determine Iran's long-term precipitation data, it is necessary to convert the data from stations into gridded data through the interpolation process. The results of diagnostic evaluations showed that if the maximum permissible error rate considered to be $\pm 15 \%$, at least 250 stations are required for the calculation of the isohyetal map of Iran. Accordingly, considering the number of active stations per day, it is possible to calculate the isohyetal maps of Iran with an error rate of $<15 \%$ for the period of 
1970 to 2016 (i.e. 46 years, equaling 16801 days). Thus, the data were collected from 1970 to 2016. In evaluations, according to the change in the number and spatial distribution of stations along with the data interval and the average distance between stations, the pixels of daily precipitation maps of Iran were made with a resolution of $10 \mathrm{~km}$. According to the existing extensive studies on various interpolation methods for obtaining the isohyetal maps of Iran (Masoudian et al. 2015; Masoudian 2008; Asakereh 2008), the Global Kriging Interpolation method with linear semivariogram model was used for interpolation. Kriging is theoretically the Optimum Linear Unbiased Estimator. The projection system of this database can be a Conical Lambert system. With these cartographic features and ten kilometers of spatial resolution, geographical grid dimensions of the dataset were obtained with dimensions of $205 \times$ 167. The total number of cells in this grid was 34235, out of which 16203 were located within the borders of the main land of Iran. On the other hand, regarding the start and end of (1970 to 2016) of the dataset, consisting of 16801 days, the final dimensions of the dataset were $167 \times 205 \times 16801$. Using this database, the temporal and spatial behavior of precipitation within the Iranian borders can be studied.

In this study, the duration of precipitation in Iran was evaluated. To this end, days with a precipitation rate of higher than $1 \mathrm{~mm}$ were considered as rainy days. After determining the rainy days, the frequency of rainy days was also examined. Consecutive days with precipitation of more than $1 \mathrm{~mm}$ were identified as precipitation sequences. After identifying precipitation duration, two approaches were considered to analyze the findings:

1. Frequency analysis of various precipitation duration and the share of precipitation of each duration in the annual precipitation rate were investigated. In addition, the linear trend model of the frequency of maximum duration was analyzed by conventional methods under linear trend evaluation (Asakereh 2007; Mudelsee 2019). The linear trend function is defined as follows (Box et al, 2016):

$$
Z_{t}=\alpha+\beta t
$$

Where, $Z_{t}$ is the precipitation rate during time $t(t=1,2, \ldots, n) . \alpha$ is the y-intercept of trend line and $\beta$ is the slope of the trend line. $\alpha$ and $\beta$ are usually calculated by the least squares method. 
2. Spatial analysis and modeling of rainy days and their duration were performed based on multivariate regression. Using regression equations, in addition to quantifying the effect of geographical coordinates (longitude $(\lambda)$ and latitude $(\varphi)$ ) and topographic factors (altitude $(h)$, slope direction $(A)$ and slope rate $(S)$ ), as independent factors, the effect of each factor on the studied element can be obtained (Asakereh et al. 2021 a). Here, the effect of these factors on the dependent factor (once frequency of precipitation durations and once the share (role) of each duration) was measured by multivariate regression.

Multivariate regression determines the variance of the dependent variable through the variance participation of two or more independent variables. If $k$ independent variable, $x_{i k}$, is used to justify $y$ in the equation, the multivariate regression equation will be as follows (Asakereh 2011):

$$
y=a+\sum_{i=1}^{k} b_{i} x_{i}+e
$$

In general, a multivariate model shows the dependent variable in a multidimensional space. In this equation, $a$ is the y-intercept, $b_{i}$ is expected variation for $y$ per unit change of $i_{t h}$ factor, provided that the other factors are constant. Multivariate regression coefficients were estimated using the least squares error method.

\section{Discussion}

\subsection{General characteristics of precipitation in Iran}

Fig $2 \mathrm{~A}$ shows the average annual precipitation in Iran during the study period. As can be seen from Fig 2A, the distribution of heights played an important role in the precipitation distribution in Iran. The maximum precipitation rates matched the precipitation distribution of Alborz (west-east direction) and Zagros (northwestsoutheast direction) mountains and corresponded to the windward slope of these mountainous areas. The average precipitation rate also followed the trend of these heights and distinguishes the areas with high-precipitation from the areas with lowprecipitation in the center, east and southeast. The long-term spatial average of precipitation is $249.2 \mathrm{~mm}$, which are shown with a thick-lined curve in the map. According to Asakereh et al. (2021 a), the general spatial trend of precipitation 
decreases from west to east and from north to south. The maximum precipitation was observed in the Caspian region and the Zagros ridges. Fig 2B also shows the average frequency of rainy periods in the country. It should be noted that in this study, the rainy period is from 1 to $\mathrm{n}$ days during which it was raining continuously. Each rainy period is separated from the next by at least 1 dry day. As can be seen from fig $2 \mathrm{~B}$, most of the rainy periods were observed on the northern coast of the country. After the northern coasts, the northwestern, northeastern parts and highlands of the Zagros had the highest numbers of rainy periods. The central, eastern and southeastern parts had the lowest precipitation periods. Therefore, it can be indicated that rainy periods, like annual rainfall, had a decreasing spatial trends from west to east and from north to south. Asakereh et al (2020) attributed the spatial trend of precipitation in Iran to the reduction of energy and rainfall of Mediterranean cyclones as well as the leeward effect of Zagros and Alborz ranges. In addition to the geographical coordinates, this decreasing trend can also be associated to the altitude.

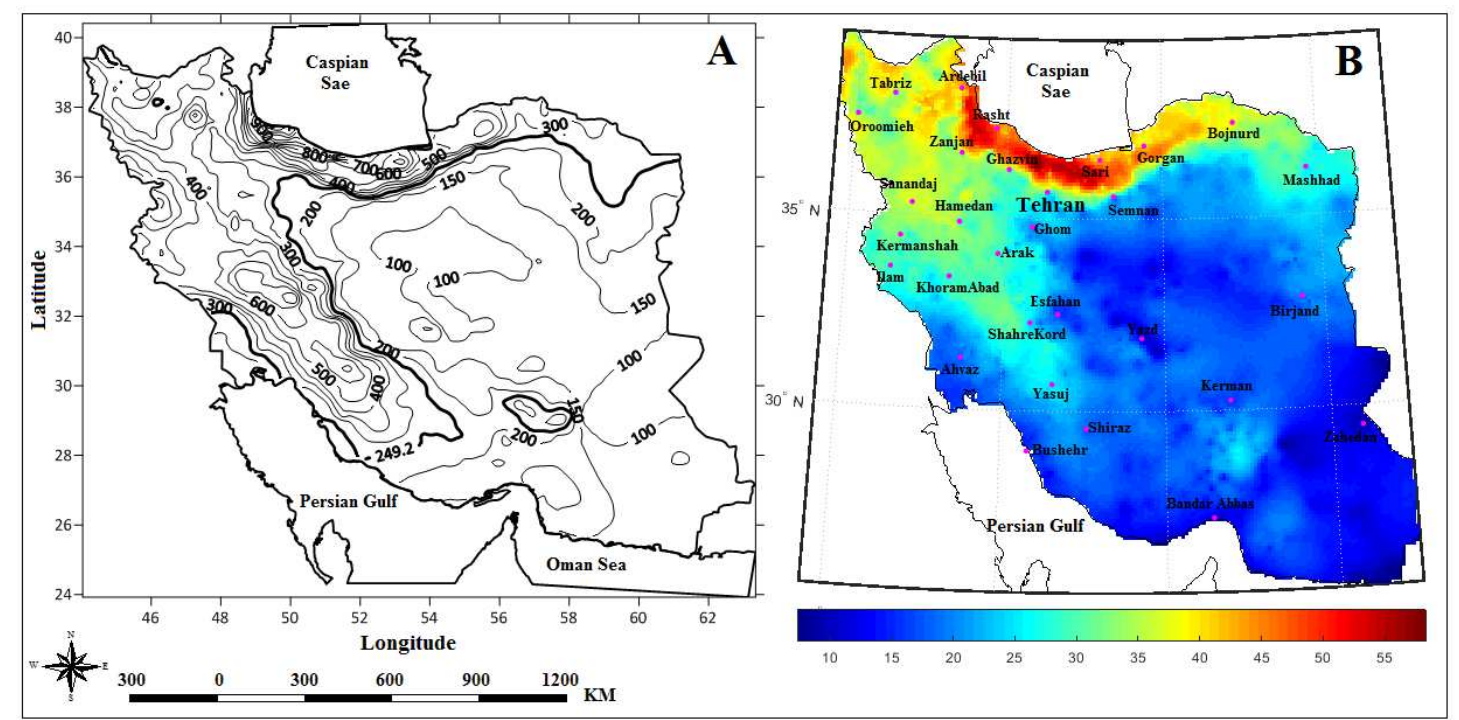

Fig 2 Long - term average of annual precipitation (A: thick line is the spatial average of precipitation) and annual average of frequency of rainy periods $(B)$ 3.2 Frequency of durations of rainy days

Analysis of precipitation rate in Iran during the study period showed that the rainy days can last from 1 to 36 days. The findings of the study showed that during the study period, the whole country has 1-4 rainy days' duration and more than $80 \%$ of the country had 5 to 7 rainy days' duration. As the number of consecutive rainy days increases, the precipitation area decreases. Therefore, in more than 13 days' duration, the receiving area diminishes to less than $10 \%$ (Table 1). This can be due to the 
locality of heavy rains. Therefore, in this paper, the duration that covers extensive areas are examined. Fig 3 shows the average frequency of 1 to 10-day duration in the study period.

Table 1: Area covered by different precipitation days (duration) and their role in annual precipitation

\begin{tabular}{|c|c|c|c|c|}
\hline \multirow{2}{*}{$\begin{array}{c}\text { Duration } \\
\text { (days) }\end{array}$} & \multirow{2}{*}{$\begin{array}{c}\text { Area } \\
\text { covered by } \\
\text { duration } \\
(\%)\end{array}$} & \multicolumn{3}{|c|}{$\begin{array}{c}\text { Share of duration of annual precipitation } \\
\text { in the country }\end{array}$} \\
\hline & & Mean & Min & Max \\
\hline 1 & 100 & 50.9 & 5.3 & 100 \\
\hline 2 & 100 & 27.2 & 0.6 & 94.7 \\
\hline 3 & 100 & 11.7 & 0.3 & 55.9 \\
\hline 4 & 100 & 5.1 & 0.2 & 48.5 \\
\hline 5 & 99.8 & 2.5 & 0.2 & 50 \\
\hline 6 & 95.4 & 1.3 & 0.1 & 27.5 \\
\hline 7 & 80.7 & 0.6 & 0.1 & 14.3 \\
\hline 8 & 63.4 & 0.3 & 0.2 & 25 \\
\hline 9 & 46.3 & 0.2 & 0.2 & 9.3 \\
\hline 10 & 32.1 & 0.1 & 0.3 & 12.2 \\
\hline 11 & 21.7 & 0.1 & 0.2 & 5.5 \\
\hline 12 & 14.8 & 0 & 0.3 & 5.4 \\
\hline 13 & 11.9 & 0 & 0.4 & 7.1 \\
\hline 14 & 6.4 & 0 & 0.5 & 3.5 \\
\hline 15 & 6.1 & 0 & 0.5 & 7.7 \\
\hline 16 & 3.5 & 0 & 0.3 & 3.2 \\
\hline 17 & 2.3 & 0 & 0.6 & 4.3 \\
\hline 18 & 2 & 0 & 0.6 & 3.1 \\
\hline 19 & 0.8 & 0 & 0.9 & 1.9 \\
\hline 20 & 1 & 0 & 0.7 & 3.3 \\
\hline 21 & 1.2 & 0 & 0.5 & 2.2 \\
\hline 22 & 0.5 & 0 & 1 & 3 \\
\hline 23 & 0.8 & 0 & 0.9 & 2.8 \\
\hline 24 & 0.5 & 0 & 1.1 & 2.7 \\
\hline 25 & 0.4 & 0 & 0.9 & 2.5 \\
\hline 26 & 0.2 & 0 & 1.1 & 2 \\
\hline 27 & 0.3 & 0 & 1.9 & 2.5 \\
\hline 28 & 0.3 & 0 & 1.4 & 2.9 \\
\hline 29 & 0.2 & 0 & 1 & 2 \\
\hline 30 & 0.1 & 0 & 1.1 & 2.2 \\
\hline 31 & 0.006172 & 0 & 0 & 0 \\
\hline 32 & 0 & 0 & 0 & 0 \\
\hline 33 & 0.006172 & 0 & 0 & 0 \\
\hline 34 & 0.006172 & 0 & 0 & 0 \\
\hline 35 & 0 & 0 & 0 & 0 \\
\hline 36 & 0.006172 & 0 & 0 & 0 \\
\hline
\end{tabular}


One-day duration of precipitation had the highest frequency among all the duration of precipitation in the country. The highest frequency of this duration was observed in the northern parts of the country (from northwest to northeast), and towards the south, the frequency of one-day duration of precipitation decreased (Fig 3). Due to the humidity of the Caspian Sea, the northern coasts, and the direction of westerlies and the humidity of these systems, in the northern half of the country, the conditions were more favorable for precipitation. The frequency of one-day duration of precipitation was at its minimum level in the southeast of the country and the frequency of this duration is $<5$ times a year on average. However, in the highlands of the southern half of the country, the frequency of one-day duration of precipitation was slightly higher than that in the surrounding areas. This may be due to the slope convection of precipitation in the highlands (Kavyani and Alijani 2001). In some parts of the country, especially in the central, eastern and southeastern regions, all annual precipitations were in the form of one-day duration of precipitation (Table 1).

In two-day duration, the maximum frequency of precipitation was limited to the northern coasts of the country. The frequency of this duration, nevertheless, was less than one-day duration. It is noteworthy that the Zagros and Alborz ranges had significant influence on this duration. Therefore, the highlands of Zagros and Alborz had an average of more than six sets of two-day duration of precipitation per year. This frequency increased at higher altitudes by 10 or more days.

The three-day duration of precipitation occurred most frequently in the northern coasts of the country. However, there was less duration in the eastern parts of the coast and the central parts, especially the western coasts, the frequency of three-day duration of precipitation was the highest. The Zagros and Alborz heights also played an important role in this duration, and at higher heights, the frequency of three-day duration of precipitation increased.

From four to ten-day duration of precipitation, in the northern coasts of the country (especially, in the southwest of the Caspian Sea) the frequency of duration reached the maximum. It should be noted, however, that as the number of precipitation days increased, their frequencies and areas decreased (Fig 3). Also, the frequency of higher 
duration was limited to the highlands. Darand (2018) also showed the role of altitudes in the duration of precipitation in Kurdistan province, Iran.

During the study period, the duration of precipitation $\geq 4$ days was not observed in a large southern and eastern part of the country, and this duration was more common in the northern, northwestern parts and highlands.

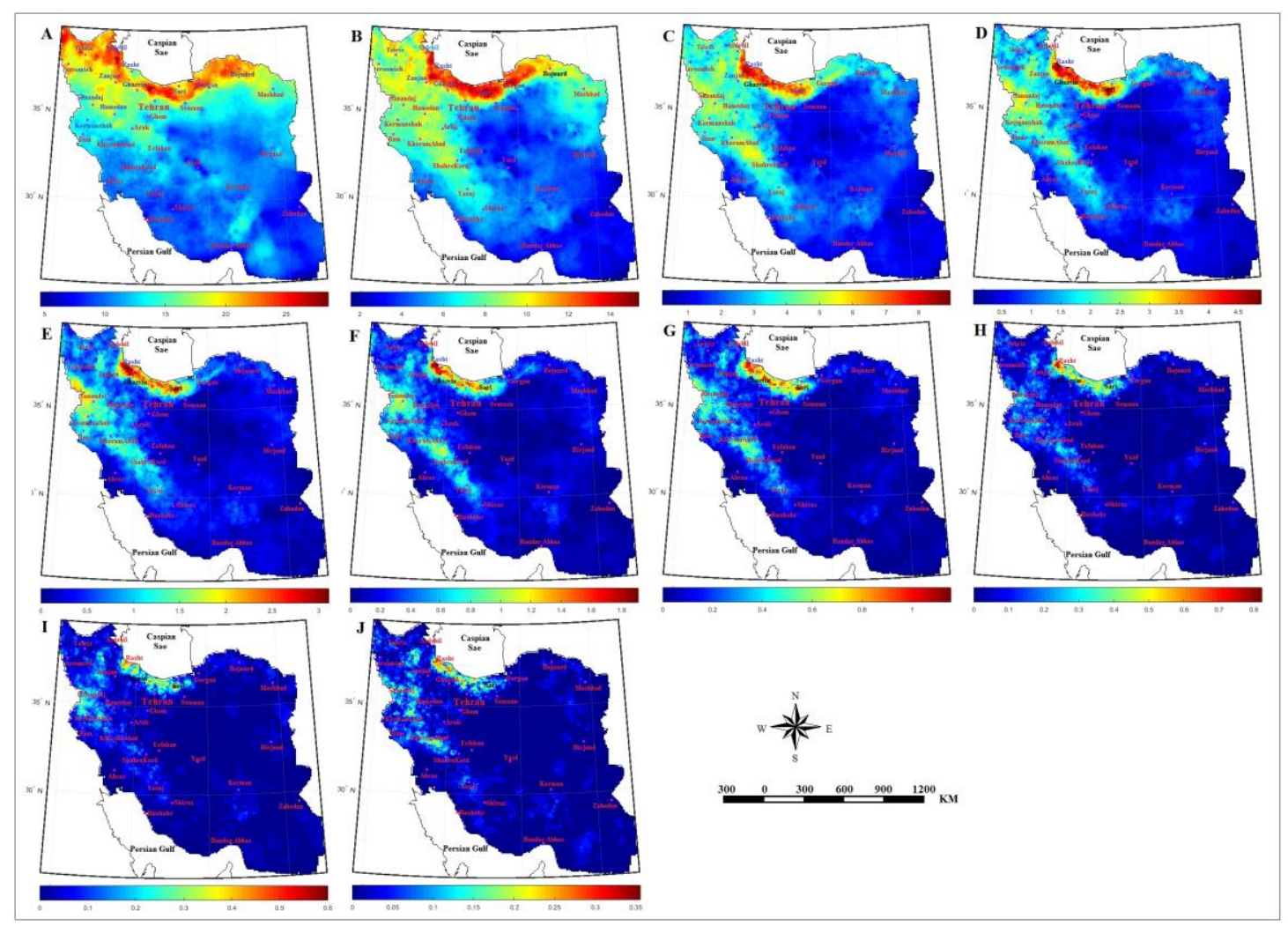

Fig 3 Average frequency of one to ten-day duration of precipitation in the under study period (1970 to 2015)

Fig 4 shows the frequency trend of one- to ten-day duration of precipitation of. oneday duration of precipitation in the southeast of the country, southwest of Sistan and Baluchestan province (southeast of Iran) and east of Hormozgan province (south of Iran) had a significant increasing trend. RahimZadeh et al. (2011) also showed that in Hormozgan province, the precipitation occurred in fewer days; therefore, the phenomenon of relatively heavy rainfall in the province increased. The increase in the frequency of one-day precipitation can be attributed to the increase in the number of local precipitation due to global warming. There was an increasing trend in the two to three-day precipitation in the central, northwestern and western parts of the country. 


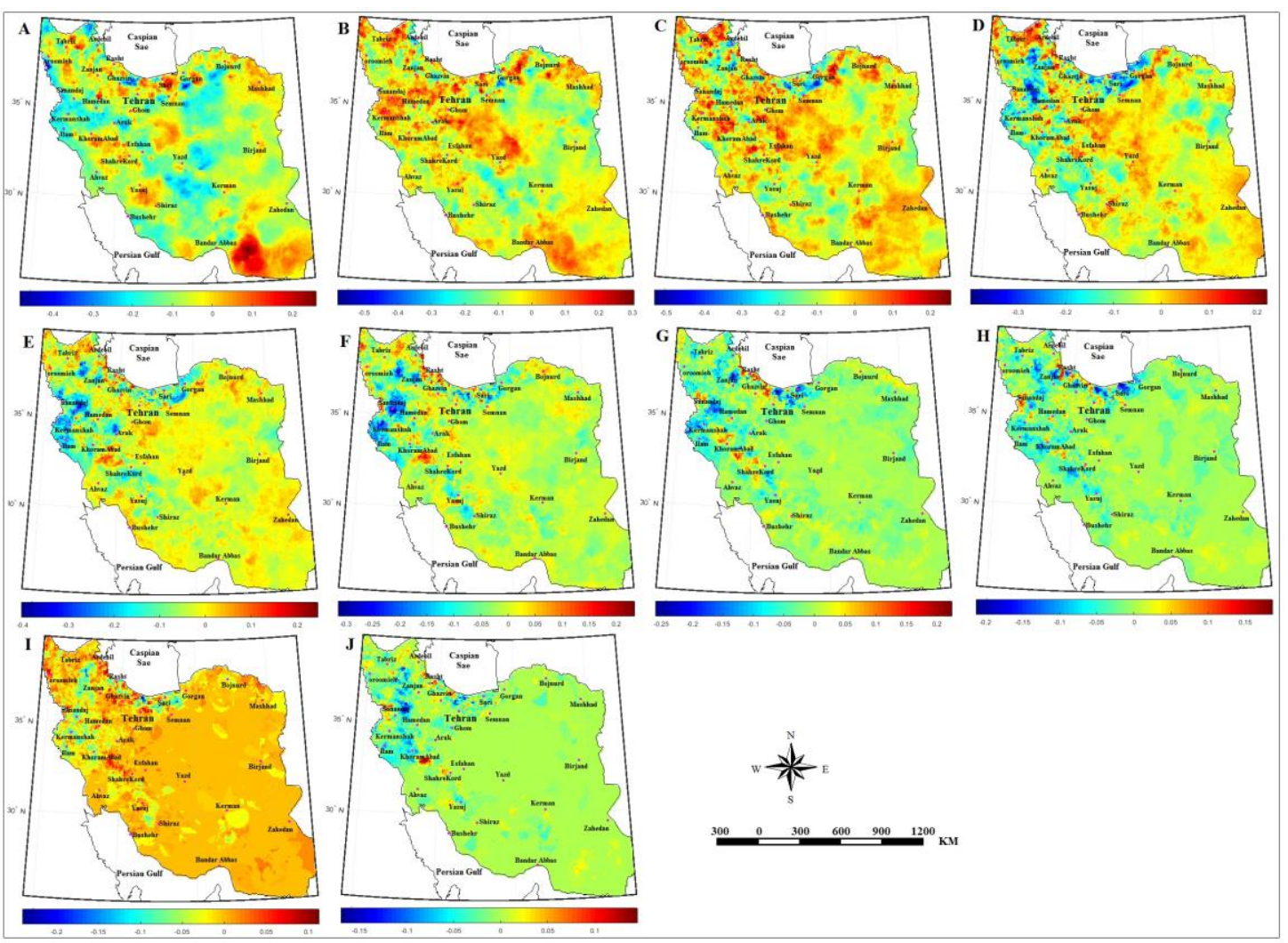

Fig 4 Frequency of one to six-day duration in the under study period (19702015)

\subsection{Share of various cases of duration of rainy days}

The share of each duration of precipitation in this study is the percentage of the annual precipitation in each duration in different parts of the country. Fig 5 show the average share of one to ten-day duration of annual precipitation.

Some parts of the country received all of their annual precipitation from one-day duration. These parts include the central, southeastern and southern areas which are the least wet parts of the country. In the central parts, the distance from water bodies and the Zagros highlands play an effective role in the precipitation shortage (Alijani 2008). Locating leeward the Zagros mountain range, prevents the impact of westerly winds on this part of the country (Masoudian and kavyani 2008; Sotoudeh et al. 2019). In the southern coasts, subtropical high pressure (STHP) is an obstacle to the formation of precipitation in these areas, as in these parts, even in the cold season, STHP is active (Alijani 1996). Nazaripour et al. (2011) also showed that in large parts of Iran experienced one-day duration of precipitation. According to their study, precipitation with one to three-day duration in the eastern regions was more prevalent, while precipitation with longer duration of more than 3 days in the western half of the 
country was more common. In the northern coasts as well as in the highlands of the Zagros, one-day duration of precipitation had the lowest share of annual precipitation (Fig 5). These areas were the rainiest areas of the country, respectively (Alijani et al. 2008), in which the precipitation showed a decreasing trend in one-day duration. Therefore, it can be noted that the minimum duration in low-precipitation areas and longer duration in higher-precipitation areas include significant shares of precipitation rates. The results of a study by Nazaripour et al. (2011) are also in line with those of the present study. As the precipitation period lengthens, the share of annual precipitation duration decreases. Therefore, in the maximum duration, this share reaches the lowest possible value and is only slightly higher than zero. Precipitation with minimal duration appears to be due to large-scale atmospheric systems, as short duration of precipitation affects a wider area and accounts for more annual precipitation. Nazaripour (2014) also showed that short duration of precipitation include the majority of rainfall and rainy days throughout Iran and long duration include a limited number of rainfalls locally.
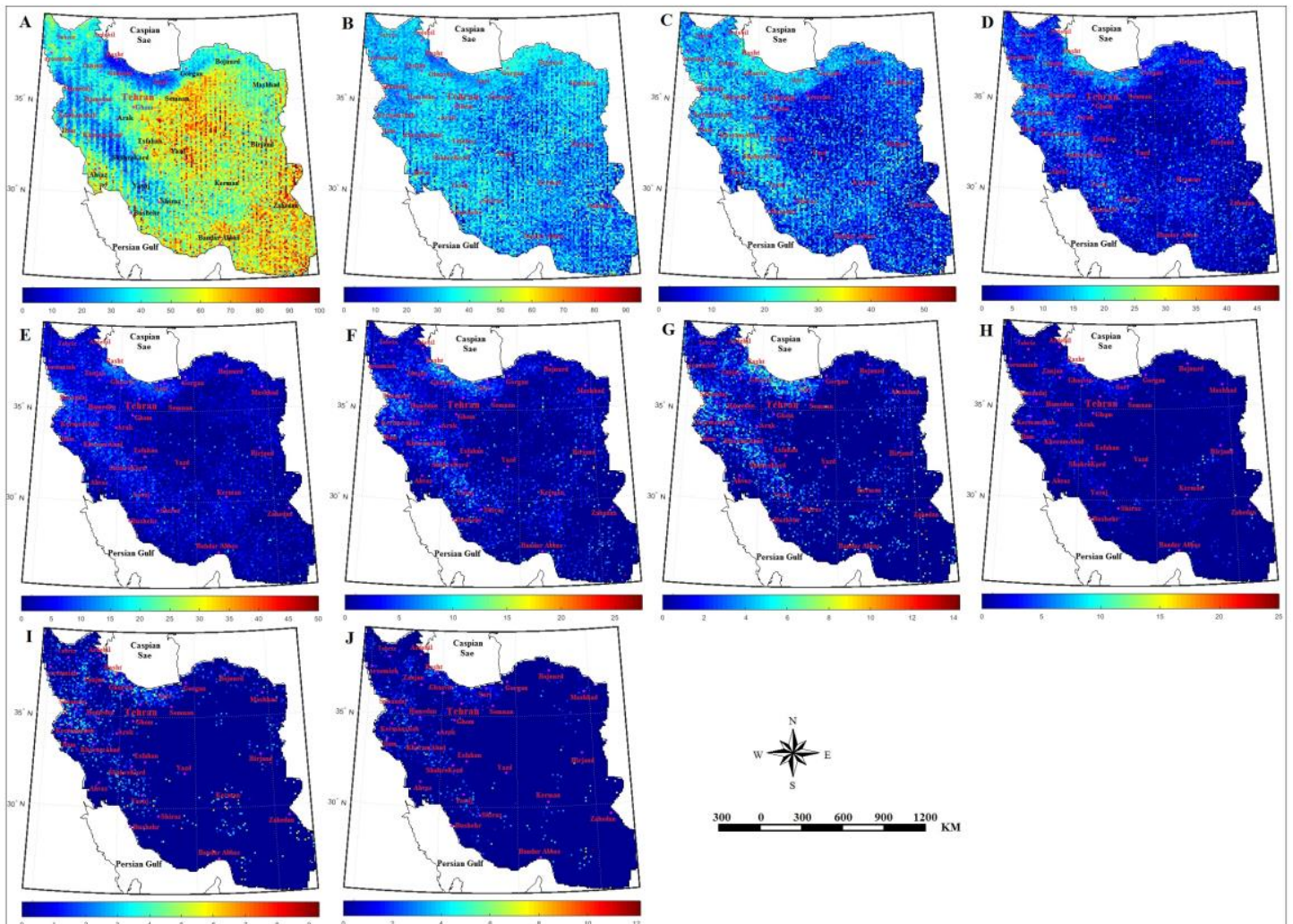

Fig 5 Average share of one to ten-day duration in annual precipitation rate during the under study period (1970- 2015) 
The increase in the frequency of short duration in the west of the country can be attributed to the activity of the Sudanese systems. According to Lashkari and Mohammadi (2019), the increasing trend of short duration in the west of Iran was due to the shorter duration of the Sudanese systems in these areas. A decreasing trend of frequency of duration could be observed in large parts of the country. This can be attributed to the decreasing moisture of advection in the country (Dostkamyan et al. 2015). Decrease in the frequency of precipitation duration means an increase in dry duration, a phenomenon which Asakereh and Tarkarani (2020) attributed to changes in STHP and cyclone redirections. Asakereh et al. (2019) also investigated the reduction of the frequency of incoming cyclones and Jahanbakhsh et al. (2021) investigated the redirection of the cyclones entering the country in relation with the decrease of precipitation in the southwest. The results of the study conducted by Fatahi and HejaziZadeh (2006) are also in line with those of the present study. Their study showed that dry and wet periods had a strong relationship with the frequency of different types of air masses. The increase in the frequency of $>5$-day precipitation in many parts of the country in the central, eastern and southeastern parts was almost without a particular trend, since in these areas precipitation often lasted fewer than 5 days; therefore, no trend was observed in these areas. According to the previous studies (Nazaripour and Karimi 2013), the share of short-duration in annual precipitation was increasing. Nazaripour and Karimi (2013) also showed an increasing trend in the share of short- duration of the annual precipitation; which led to a temporal compactness in the precipitation of the country.

\subsection{Trend of Maximum duration of rainy days}

During the study period, the highest duration in the country was 36 consecutive days of rainfall. In some parts of the country, the highest duration was 4 days, mostly in the central parts of the country. In a large part of the country, the maximum duration of precipitation in the under investigation period was fewer than 10 days. In small parts of the west, northwest and north of the country, the maximum duration was more than 25 days. In these areas, the maximal duration experienced a decreasing trend. In areas where the maximal duration was short, the number of maximal duration increased. It should be noted that the largest increasing trend of maximal duration could be observed in the northwestern border areas and the northern coasts of the country. The decreasing trend of maximal duration may be due to the fact that in these areas, 
precipitation occurred in a limited number of days. This means that a significant share of the precipitation in these areas occurs in one or a few days (minimum frequency) (Fig 6). This can cause climatic hazard and lead to floods. $22.6 \%$ of the country had an increasing trend and $77.4 \%$ had a decreasing trend of annual maximal duration. Asakereh et al. (2020) also showed a decreasing trend in the frequency of rainy days based on high percentiles of precipitation. According to their study, the frequency of dry days had an increasing trend. An increase in dry days can reduce precipitation duration.

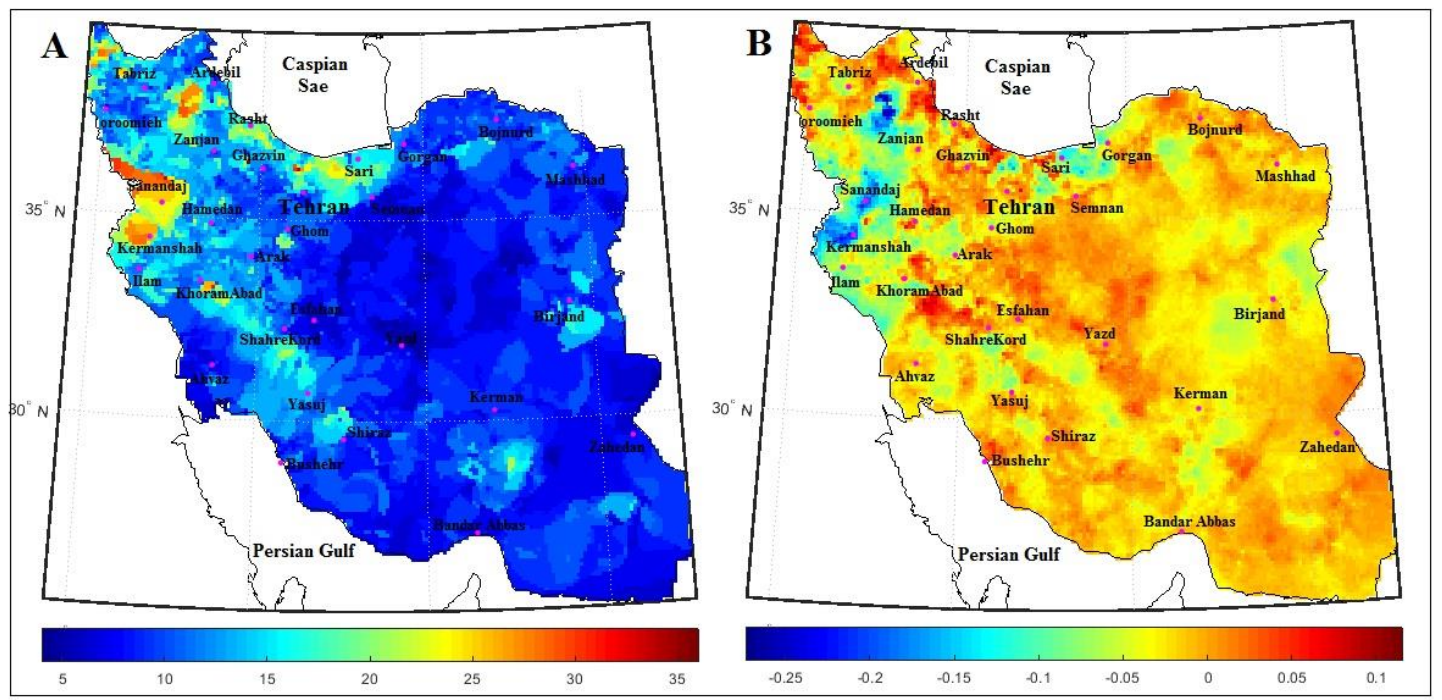

Fig 6 The longest precipitation duration (days) during the under study period and the trend of the longest precipitation duration (days/year) 3.5 Spatial analysis and modeling of precipitation duration

Multivariate regression was used to investigate the effect of spatial factors on the frequency of precipitation duration. Spatial factors used in this study are latitude and longitude, altitude, slope and terrain slope. For the sake of brevity, only the multivariate regression equation for one to ten-day duration and the share of one to ten-day duration of annual precipitation were included in Tables 2 and 3. As can be seen from Table 2, latitude and longitude were the most important factors affecting the spatial distribution of the frequency of one to ten-day duration, respectively. The role of these factors were more prominent in short duration. Latitude and longitude were related to the frequency of precipitation duration in direct and inverse manners, respectively. In other words, with the increase in latitude, the frequency of precipitation duration increase and with the increase in longitude, the frequency of precipitation duration decrease. The findings of the study conducted by Asakereh et 
al. (2021 a) substantiates those of the present study and the inverse and direct relationship of precipitation rate of the country with longitude and latitude, respectively. However, in their study, longitude had more significant effect on precipitation. The effect of latitude is more significant on minimal duration. In longer duration, the role of longitude had become more prominent. Regarding the share of precipitation caused by each duration latitude and longitude were the most important factors affecting the frequency of duration, respectively. A noteworthy point is the inverse role of latitude and the direct role of longitude in the share of one-day precipitation duration (Table 3). The share of one-day duration in annual precipitation decreased as the latitude increased and it increased as the longitude increased, which indicates the importance of the role of one-day precipitations in water supply of arid regions of the country. In other cases of duration of rainy days, the opposite was true.

Table 2: Multivariate regression equations of spatial factors and frequency of one to ten-day duration

\begin{tabular}{|cc|}
\hline spell (day) & Multi Regressions \\
\hline 1 & $P_{S 1}=-13.27+0.93 \varphi-0.09 \lambda+0.0004 h+0.13 S+0.00002 A$ \\
2 & $P_{S 2}=0.09+0.43 \varphi-0.16 \lambda+0.0004 h+0.12 S+0.0008 \mathrm{~A}$ \\
3 & $P_{S 3}=4.9+0.13 \varphi-0.13 \lambda+0.0003 h+0.07 S+0.0003 \mathrm{~A}$ \\
4 & $P_{S 4}=2.9+0.06 \varphi-0.07 \lambda+0.0001 h+0.04 S+0.0002 A$ \\
5 & $P_{S 5}=1.9+0.02 \varphi-0.04 \lambda+0.00009 h+0.02 S+0.00008 A$ \\
6 & $P_{S 6}=0.99+0.01 \varphi-0.02 \lambda+0.00005 h+0.01 S+0.00004 A$ \\
7 & $P_{S 7}=0.5+0.007 \varphi-0.01 \lambda-0.00002 h+0.007 S+0.00001 A$ \\
8 & $P_{S 8}=0.22+0.004 \varphi-0.006 \lambda+0.00001 h+0.004 S+0.000004 A$ \\
9 & $P_{S 9}=0.12+0.003 \varphi-0.0037 \lambda+0.000006 h+0.002 S-0.000001 A$ \\
10 & $P_{S 10}=0.12+0.001 \varphi-0.002 \lambda+0.000004 h+0.001 S+0.000002 A$ \\
\hline
\end{tabular}

Table 3: Multivariate regression equations of spatial factors and the share of one to ten-day duration of annual precipitation

\begin{tabular}{|cc|}
\hline Spell (day) & Multi Regression \\
\hline 1 & Ratio $_{S 1}=1.7-0.76 \varphi+1.47 \lambda-0.003 h-0.6 S-0.005 \mathrm{~A}$ \\
2 & Ratio $_{S 2}=23.3+0.34 \varphi-0.15 \lambda+0.0005 h+0.04 S+0.001 \mathrm{~A}$ \\
3 & Ratio $_{S 3}=30.06+0.13 \varphi-0.45 \lambda+0.001 h+0.16 S+0.002 \mathrm{~A}$ \\
& \\
4 & Ratio $_{S 4}=18.8+0.09 \varphi-0.33 \lambda+0.0007 h+0.15 S+0.001 \mathrm{~A}$ \\
5 & Ratio $_{S 5}=12.2+0.057 \varphi-0.22 \lambda+0.0005 h+0.1 S+0.0003 \mathrm{~A}$ \\
6 & Ratio $_{S 6}=5.9+0.04 \varphi-0.12 \lambda+0.0002 h+0.06 S+0.0004 \mathrm{~A}$ \\
7 & Ratio $_{S 7}=3.15+0.33 \varphi-0.07 \lambda-0.0001 h+0.04 S+0.00001 \mathrm{~A}$
\end{tabular}




$\begin{array}{|cc|}8 & \text { Ratio }_{S 8}=1.55+0.017 \varphi-0.03 \lambda+0.00008 h+0.02 S+0.0001 A \\ 9 & \text { Ratio }_{S 9}=0.8+0.017 \varphi-0.024 \lambda+0.00005 h+0.01 S-0.000006 A \\ 10 & \text { Ratio }_{S 10}=0.89+0.004 \varphi-0.02 \lambda+0.00002 h+0.008 S+0.00003 A\end{array} \mid$

\section{4 summery and Conclusion}

In this study, precipitation gridded data were used for the period of 1971 to 2016 and a daily data matrix was formed for 16436 days. In addition, the frequency of rainy days was investigated as a characteristic of precipitation and its variations were analyzed. The study showed that during the under study period, the country's precipitation had duration of 1 to 36 days. One-day duration had the highest number of repetitions and covered the widest area, while thirty six-day duration had the lowest number of repetitions and covered the smallest area. Due to the importance of shorter duration, one to ten-day duration were analyzed in this study. The findings showed that one-day duration had the highest share in annual precipitation. In some parts of the central, eastern and southeastern areas, all annual precipitation resulted from oneday duration. In other words, areas with low precipitation received a high percentage of annual precipitation (in some parts, all annual precipitation) from one-day duration. In areas with high-precipitation, one-day duration included a small share in the annual precipitation supply. The frequency of short-term duration, especially two-day duration, was increased in large parts of the country, and long-term duration was decreased in many areas. The share of short-term duration also increased. The results showed that latitude and longitude had the most significant impact on the frequency distribution of rainy-day duration, respectively. 


\section{Declarations:}

-Conflict of Interest : The authors declare that there is no conflict of interest while conducting this research.

-Funding Statement: There was no specific grant for this research from any funding source.

-Author's Contribution: We, the authors, contributed to the research. Hossein Asakereh performed the study conception, design, and data analysis. Material preparation, data collection were performed by Saeideh Ashrafi. The first draft (in Persian) of the manuscript was written by Saeideh Ashrafi. The final versions of the manuscript (in English) was written by Hossein Asakereh.

-Availability of data and material: The data of daily precipitation was provided from Islamic Republic of Iran Meteorological Organization (IRIMO) which have been described in details under the heading of " 2.2 data" in this manuscript.

-Code availability: MATLAB code used in this study for analyzing the data and preparing the required maps of the study area. The code is written according to the method is described in details under the heading of "2.3 Method" section.

-Ethics approval: The manuscript is original and is not submitted to another journal for simultaneous consideration neither have been published elsewhere in any form or language (partially or in full). Results are presented clearly, honestly, and without fabrication, falsification or inappropriate data manipulation. No data, text, or theories by others are presented as if we are the author's own.

-Consent to participate: We, the authors, understand that any information we submit for this study will be treated as confidential, and that we have all contributed to the research.

-Consent for publication: We, the authors, provide our consent for this research to be published in Theoretical and Applied Climatology journal, which include maps and information within the text.

Acknowledgements: We would like to thank the Islamic Republic of Iran

Meteorological Organization (IRIMO) for providing us with the daily precipitation. 


\section{References}

1) AghaRazi H, Telvari A, DavoudiRad AA (2007), Drawing Depth - Area Duration in Markazi Province. Pajouhesh Va Sazandegi 20: N 1

2) Alijani B (1996) Climate of Iran. Payam Noor University Press, Tehran

3) Alijani B (2008) Effect of the Zagros Mountains on the spatial distribution of precipitation. J Mt Sci 5:218-231. https:// DOI 10.1007/s11629-0080126-8

4) Alijani B, Mahmoudi P, Shahvazni A, Mohammadi A (2014) Investigating the probability of rainy days' duration in Iran. Geography and Environmental Planning 25: N 56

5) Alijani B, O’Brien J, Yarnal B (2008) Spatial analysis of precipitation intensity and concentration in Iran. Theor Appl Climatol 94: 107-124. https:// DOI 10.1007/s00704-007-0344-y

6) Alizadeh A (2009) Principles of Applied Hydrology. Imam Reza University press, $27^{\text {th }}$ Reprint

7) Asakereh H (2006) Climate change. Zanjan University Press, Zanjan.

8) Asakereh H (2008) Kriging Application in Climatic Element Interpolation a Case Study: Iran Precipitation in 1996.12.16. Geography and Development 6: N 12. https://doi: 10.22111/gdij.2008.1241

9) Asakereh H (2011) Foundations of Statistical Climatology. Zanjan University Press, Zanjan

10) Asakereh H (2013) Analyses the Trend of Dry and Wet Winds in Zanjan. Geography and Development 11: N 31. https://doi:10.22111/gdij.2013.793

11) Asakereh H, Jahanbakhsh S, Ashrafi S (2019), On the frequency changes of cyclones affecting precipitation in the Rood Zard basin, Iran. Arabian Journal of Geosciences 12:413. https://doi.org/10.1007/s12517-019-4523-9

12) Asakereh H, Masoudian SA, Tarkarani F (2020) Long - term trend detection of annual precipitation over Iran in relation with changes in frequencies of daily extreme precipitation. Journal of geography and environmental hazard 9: N 36. https://doi: 10.22067/geoeh.2021.67028.0

13) Asakereh H, Masoudian SA, Tarkarani F (2021 a) A Discrimination of Roles of Internal and External Factors on the Decadal Variation of Annual Precipitation in Iran over Recent Four Decades (1975-2016). Physical Geographical $\quad$ Research $\quad 53: \quad$ N https://doi:10.22059/jphgr.2021.304776.1007529

14) Asakereh H, Masoudian SA, Tarkarani F (2021 b) An investigation of Decadal variation of Iran precipitation over four decades (1976-2016). $\begin{array}{lllll}\text { Geography } & \text { and } & \text { planning } & \end{array}$ http://dx.doi.org/10.22034/gp.2020.41308.2680

15) Asakereh H, Tarkarani F (2020) Some descriptive features and long - term changes of dry season over Iran. Geography and Development 18: N 58. https://doi :10.22111/gdij.2020.5324

16) Behyar M B, Khazaei M, Ghaemi H (2013), The Analysis of Precipitation Time Regime in Great Karoon Basin. GeoRes 28 (1):1-12.

17) Bichet A, Diedhiou A (2018) West African Sahel has become wetter during the last 30 years, but dry spells are shorter and more frequent. Climate Research 75(2): 155-162. https:// DOI: 10.3354/cr01515 
18) Box G E P, Jenkins G M, Reinsel G C, Ljung G M (2016) Time Series Analysis Forecasting and Control. Fifth Edition, John Wiley \& Sons publication

19) Darand M (2018) Spatial Analysis of Precipitation Persistency in Kurdistan Province. Geography and development 52. https://doi: 10.22111/gdij.2018.4125

20) Dostkamyan M, Mohammadi bigdeli F, kohpayehi N (2015) The Analysis of Monthly moisture advection changes in Iran's atmosphere over the recent half-century. researches in Geographical Sciences 15 (39) :139-152

21) Douguedroit A (1987) The variation of dry spells in Marseilles from 1865 to 1984. J Climatol 7:541-551. https:// DOI: 10.1002/joc.3370070603

22) Duan Y, Ma Z, Yang Q (2017) Characteristics of consecutive dry days variations in China. Theor Appl Climatol 130:701-709. https:// DOI 10.1007/s00704-016-1984-6

23) Fatahi I, HejaziZadeh Z (2006) Temporal and Spatial Air Masses and its Application in Monitoring Dry and Wet Periods (Spells) in Southwest Basins of Iran. Geographical Research 21: N 81

24) Ghafouriam R, Telvari A (2010) Determination of Depth - Area Duration Rainfall Curves and Relationships in Khorasan Province Range and Watershed Management 63: N 2

25) Gholizadeh M H, Hamidi S (2020) The evaluation of rainfall duration variability in Kurdistan Province. Geography and Planing 24: N 71. http://dx.doi.org/10.22034/gp.2020.10541

26) Jahanbakhsh S, Ashrafi S, Asakereh H (2021) Examining decadal changes in cyclones associated with precipitation in the Zard Rud basin. Geography and Planing 75. http://dx.doi.org/10.22034/gp.2021.10842

27) Kavyani M R, Alijani B (2001), The Foundations of Climatology. Samt Press, eight edition

28) Kutiel H, Trigo RM (2014) The rainfall regime in Lisbon in the last 150 years. Theoretical and applied climatology 118(3): 387-403. https:// DOI 10.1007/s00704-013-1066-y

29) Lashkari H, Mohammadi F (2019) I nvestigation of Rainfall Variation of Sudan Low during the Historical Process in Southwestern Iran. Physical Geography $\quad$ Research $\quad 51: \quad N$ N https://doi:10.22059/jphgr.2019.272706.1007323

30) Lázaro R, Rodrigo FS, Gutirrez L, Domingo F, Puigdefáfragas J (2001) Analysis of a 30-year rainfall record in semi-arid SE Spain for implications $\begin{array}{llllll}\text { on } & \text { vegetation. } \mathrm{J} \text { Arid } & \end{array}$ https://DOI:10.1006/JARE.2000.0755

31) Liu C (2011) Rainfall Contributions from Precipitation Systems with Different Sizes, Convective Intensities, and Durations over the Tropics and Subtropics. Journal of Hydrometeorology 12: 394-412. https:// DOI: 10.1175/2010JHM1320.1

32) Mansuri S, Doostan R (2019) Atmospheric patterns of rainfall duration in west of Iran. Physical Geography 12: N 43 
33) Masoudian S A (2008) On precipitation mapping in Iran, Journal of Humanities, Vol.30, No. 2, PP. 69-80

34) Masoodian S A, Rayatpishe F, Keykhosravi Kiani M S (2015) Introducing the TRMM and Asfezari precipitation database: A comparative study, Iranian Journal of Geophysics, No. 4, PP. 15-31.

35) Masoudian SA, kavyani M R (2008) Climatology of Iran, Isfahan Univercity Press. First Edition

36) Mudelsee M (2019) Trend analysis of climate time series: A review of methods. Earth-Science Reviews 190: 310-322. https:// doi.org/10.1016/j.earscirev.2018.12.005

37) Naseri M, Modarres R (2009) Dry spell trend analysis of Isfahan Province, Iran. Int. J. Climatol 29: 1430-1438. https:// DOI: 10.1002/joc.1805

38) Nazaripour H (2014) Regions of Iran with Persistence of Precipitation. Geography and Development 12: N 36. https:// doi:10.22111/gdij.2014.1718

39) Nazaripour H, Karimi Z (2013) Detection Changes in Precipitation Daily Persistence's Share in the Supply of Iran's Rainy Days and Precipitation Amount. Journal of Geographical Sciences 12: N 27

40) Nazaripour H, Khosravi M, Masoodin S A (2011) Spatial patterns of Importance of Iranian Rainfall Persistency. Arid Regions Geographic Studies. 2011; 1, N3.

41) Nunn R (1929) Duration of Rainfall at Baltimore. MD, Monthly Weather Review, pp 50-52.

42) RahimZadeh F, HedayatiDezfuli A, PourAsgharian A (2011), Assessments of the Process and Mutation of Limit Indices of Temperature and Precipitation in Hormozgan Province. Geography and Development 9: N 21. https://doi: 10.22111/gdij.2011.583

43) Ratan R, Venugopal V (2013) Wet and dry spell characteristics of global tropical rainfall. Water Resources Research 49: 3830-3841. https:// doi:10.1002/wrcr.20275

44) Romero R, Guijarro AJ, Ramis C, Alonso S (1998) A 30-year (19641993) daily rainfall data base for the Spanish Mediterranean regions: first exploratory study. Int $\mathrm{J}$ Climatol 18:541-560. https://DOI: 10.1002/(SICI)1097-0088

45) Shands A L (1947) Maximum Observed Rainfalls in the United States for Durations to 72 Hours and Areas to 100000 Square Miles. Bulletin American Meteorological Society 28: 233-236.

46) Singh N, Ranade A (2010) The Wet and Dry Spells across India during 1951-2007. Journal of Hydrometeorology 11: 26 -45. https:// DOI: 10.1175/2009JHM1161.1

47) Sotoudeh F, Alijani B, Saligheh M, Akbari M (2019) The Influence of Zagros Mountains on Iran's Rainfall Cyclones. Physical Geography Research 50: N 4. https://doi: 10.22059/jphgr.2019.245032.1007142

48) Vinnarasi R, Dhanya C T (2016) Changing characteristics of extreme wet and dry spells of Indian monsoon rainfall. J Geophys Res Atmos 121: 2146-2160. https:// doi:10.1002/2015JD024310 
49) Ye H, Fetzer E J (2019) Asymmetrical shift toward longer dry spells associated with warming temperatures during Russian summers. Geophysical Research Letters 46 (11),455-462. https://doi.org/10.1029/2019GL084748 